\title{
Interinstitutional perspectives on contract cheating: a qualitative narrative exploration from Canada
}

\author{
Sarah Elaine Eaton ${ }^{1}$ (D), Nancy Chibry ${ }^{2}$ (D), Margaret A. Toye ${ }^{3^{*}}$ (D) and Silvia Rossi ${ }^{4}$ (D)
}

\author{
* Correspondence: mtoye@ \\ bowvalleycollege.ca \\ ${ }^{3}$ School of Community Studies, Bow \\ Valley College, Calgary, Alberta, \\ Canada \\ Full list of author information is \\ available at the end of the article
}

\begin{abstract}
This paper explores contract cheating from the perspectives of researchers at three post-secondary institutions in Alberta, Canada, describing their efforts to develop and advance awareness of, interventions against, and responses to contract cheating at their respective institutions. Contract cheating is when a third party produces or completes academic work for a student, and the student then presents the work as their own. The student might have personal connections to the third party, or the student might pay a fee and outsource the academic work to the third party. All three institutions are experiencing an increase in the incidence of contract cheating, which is consistent with trends at colleges and universities across Canada and the world. Contract cheating is not a new phenomenon, but it is a growing one, due in part to students having access to thousands of online companies offering to help them with their academic work. This paper examines personal narratives from four researchers and identifies five key themes: types of contract cheating, students, awareness, evidence and policy implications, and educational development.
\end{abstract}

Keywords: Contract cheating, Academic integrity, Higher education, Post-secondary, Canada

\section{Introduction}

Our project showcases perspectives from four researchers at three Alberta postsecondary institutions, using a collaborative action research approach to reflect upon and then develop interventions to advance awareness of, and responses to, contract cheating. Contract cheating (Clarke \& Lancaster, 2006) includes but is not limited to essay mills, custom writing services, assignment completion services, and professional exam takers. In short, contract cheating happens when students have someone else complete academic work on their behalf, but submit the work as if they had done it themselves.

Framed through action research, our project extends the scholarship of teaching and learning (SoTL) beyond the individual classroom (micro level) to a broader institutional (macro level) context, and extended our discussion beyond individual institutions. We situate ourselves as scholar-practitioners, each with a different role in our respective institutions. Using personal narratives, observations, and institutional documentation as data sources, we engaged informal interventions designed to help both faculty members and students develop greater awareness about what contract cheating

(C) The Author(s). 2019 Open Access This article is distributed under the terms of the Creative Commons Attribution 4.0 International License (http://creativecommons.org/licenses/by/4.0/), which permits unrestricted use, distribution, and reproduction in any medium, provided you give appropriate credit to the original author(s) and the source, provide a link to the Creative Commons license, and indicate if changes were made. 
is and why it deserves attention from a teaching and learning perspective. We conclude with practical and evidence-informed recommendations for practitioners, educational developers, and decision-makers.

\section{Conceptual framing}

Academic integrity is often examined through one of three perspectives: a) moral, b) policy and procedural, or c) educational (Adam, 2016). Advocates of academic integrity promote educational approaches to issues such as plagiarism, cheating, and other forms of academic dishonesty, with one expert calling it a "teaching and learning imperative" (Bertram Gallant, 2008, p. 6).

Framing our project as a question of teaching and learning allowed us to adopt an inclusive positionality; we included those with a traditional faculty role as well as one team member who works at a student writing centre at a university. No less important was acknowledgement of the perspectives of those among us who hold administrative roles, whose work includes managing cases of misconduct after a violation of integrity has occurred. We observed that the teaching and learning positionality of our study was sometimes in tension with administrative requirements of enacting institutional policy. In our work, we have intentionally used the word "educator" rather than "professor" or "instructor" as a way of demonstrating inclusivity within our research team. This inclusive positioning of our work is infused and embedded to a certain degree with values espoused by the SoTL research community in Canada, which firmly advocates for more egalitarian participation in SoTL, as well as a recognition of the value of the contributions of those who are not strictly faculty members. This is evidenced by the fact that the term educational developer is strongly favoured in Canada over the traditional term faculty developer, used elsewhere. The term educational is intentional in its inclusivity and meant to show that developments in education can -- and should -- occur in communities beyond the narrow scope of those whose roles identify them as faculty members (McDonald et al., 2016).

\section{Background}

Although there have been documented cases of students paying someone to complete academic work on their behalf since the 1970s, the Internet has enabled an upsurge in contract cheating, which includes but is not limited to essay mills, custom writing services, assignment completion services, and professional exam takers (Clarke \& Lancaster, 2006). Today there is debate among scholars about the definition of contract cheating. Some argue that it involves a monetary transaction between a student and a corporate provider (Rigby, Burton, Balcombe, Bateman, \& Mulatu, 2015). Others have a broader definition that includes third parties who complete work for the student but do not receive payment (Ellis, Zucker, \& Randall, 2018; Lancaster \& Clarke, 2008; Rogerson, 2017; Walker \& Townley, 2012).

We aligned our inquiry with that of the Quality Assurance Agency for Higher Education (2017) in the UK, which offers this definition: "Contract cheating' happens when a third party completes work for a student who then submits it to an education provider as their own, where such input is not permitted" (p. 1) (Fig. 1). We prefer this more inclusive definition of contract cheating because as SoTL scholars, we assert that when students engage a third party to complete their work for them, they are effectively opting out of the learning process, regardless of who is completing the work on their behalf. 
Expectation:

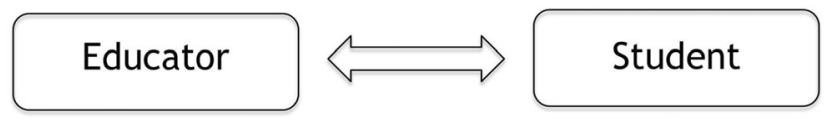

Violation:

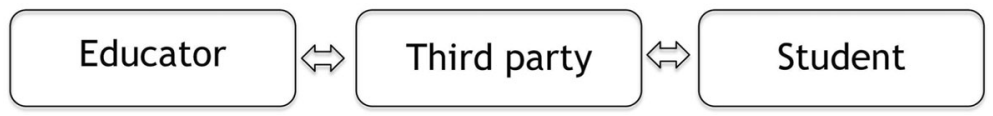

Fig. 1 Graphic representation (simplified) of how contract cheating violates the expectation of an educator that a student will complete their own work. (Adapted from Lancaster \& Clark, 2009)

Having said that, we would be remiss not to acknowledge that contract cheating is an industry that brings in hundreds of millions of dollars per year worldwide (Owings \& Nelson, 2014). Over a decade ago, scholars asserted that Canada was among the top four countries from which students bought academic work online (Clarke \& Lancaster, 2006). Later, Lancaster (2018), a leading authority in the field of contract cheating, asserted that Canada was tied with the UK for second place while the United States remained the country from which the greatest number of students placed online orders for academic work.

Studies have shown varying rates of contract cheating among students, ranging from 3.5\% (Curtis \& Clare, 2017) to over 21\% (Hosney \& Fatima, 2014). Newton (2018) found evidence to suggest that one in seven students has reported purchasing an assignment. To date, there is little empirical evidence about rates of contract cheating among Canadian students. Using Curtis and Clare's (2017) conservative estimate of $3.5 \%$ of students, and mapping that to Statistics Canada data about the total number of post-secondary students in Canada, Eaton (2018) estimated that over 71,000 postsecondary students in Canada might be engaged in some form of contract cheating.

The problem of practice that grounds the work is that contract cheating is poorly understood from a teaching and learning perspective. This is further exacerbated by a lack of research in Canada about this issue. We undertook this work as a first step towards contributing to the growing corpus of scholarship about contract cheating, using the specific lens of SoTL and making a unique contribution from the Canadian context. Thus, the purpose of our inquiry was to compare our individual experiences and perspectives relating to contract cheating in order to uncover common questions, struggles, and approaches to dealing with this complex breach not only of academic integrity but also of the expectation educators have that students engage in their own learning.

Although our work is focused on the Canadian context, we draw upon scholarship that has been undertaken in other countries, such as Australia and the UK, where research on contract cheating has not only been conducted, but has also served as a foundation upon which others can build (Bretag et al., 2019; Clarke and Lancaster, 2006; Curtis and Claire, 2017; Ellis et al. 2018; Mahmud et al., 2019).

\section{Contract cheating through the SoTL Lens}

By situating this work within the scholarship of teaching and learning (SoTL), we have drawn on the reciprocal relationship of teaching and learning at the post-secondary 
level (Boyer, 1990). O’Brien (2008) positions SoTL as "a kind of standing back. .. in order to deliberately frame and investigate what works, and what doesn't" (p. 1). A foundational concept in SoTL is that it requires a kind of "going meta" (Hutchings \& Schulman, 1999, p. 13) to investigate key questions related to teaching and learning.

A key aspect of being a SoTL researcher is that one is necessarily also an educator. Although SoTL may include theoretical perspectives, it is not purely a theoretical or academic exercise. A key objective of SoTL is to improve teaching and learning, which necessarily has a pragmatic focus. By extension then, a SoTL scholar is someone who is intensely concerned with students: what they learn, how they learn and how educators facilitate their learning in ways that are meaningful, productive and lasting (Hubball \& Clarke, 2010). In the project, we position ourselves as SOTL participant-researchers.

We have stood back from our daily professional practice to reflect deeply on a provocation made by Gallant (2008), who urged educators to reframe the question "Why are students cheating?" as "Why aren't our students learning?" (p. 6). When students hire someone to complete academic work on their behalf, they are not learning.

We subscribe to Fanghanel's (2013) notion of SoTL as a democratic and dialogic form of inquiry that invites multiple voices (academics, administrators, student support specialists) and "provides spaces for interdisciplinary and cross-institutional reflection" (p. 62; emphasis added).

One approach frequently used in SoTL is to situate an inquiry within a nested framework in which a problem of practice can be examined from one or more of these perspectives: micro (individual), meso (departmental or other institution unit), or macro (institutional) (Kalu et al., 2018; Kenny et al., 2016). Although not explicitly framed as SoTL, similar approaches have been taken by those who have written about academic integrity and misconduct (Bertram Gallant \& Kalichman, 2011). Figure 2 shows how SoTL inquiry can be framed within a nested framework.

The project is further grounded theoretically in the work of Hubball and Pearson (2013), who advocate for extending SoTL inquiry beyond individual classrooms to broader institutional contexts. We interrogated broad institutional approaches to academic integrity in general and to contract cheating in particular. Using a collaborative action research approach, we used personal narratives, observations, and institutional documentation as data sources. We have designed and used informal interventions such as hallway conversations and in-class discussions to help both faculty members and students develop greater awareness about what contract cheating is and why it deserves attention from a teaching and learning perspective. All four authors of this article concluded that this type of intervention is a start, but it needs to occur in conjunction with other practices and interventions at the departmental and institutional levels.

We acknowledge that SoTL inquiry sometimes brings together educators from different disciplines (Hubball \& Clarke, 2010) and in our case, different institutions, which can be "epistemologically challenging and empowering" (Hubball \& Clarke, 2010, p. 1). Because of this, SoTL embraces a wide range of research design approaches, including action research (Hubball \& Clarke, 2010). So to undertake our inquiry, we designed a qualitative action research SoTL project with an exploratory focus. Action research provided us with an approach for engaging in reflective inquiry for professional development and educational practice (McNiff, 2010, 2013, 2014; Simmons, Eaton, 


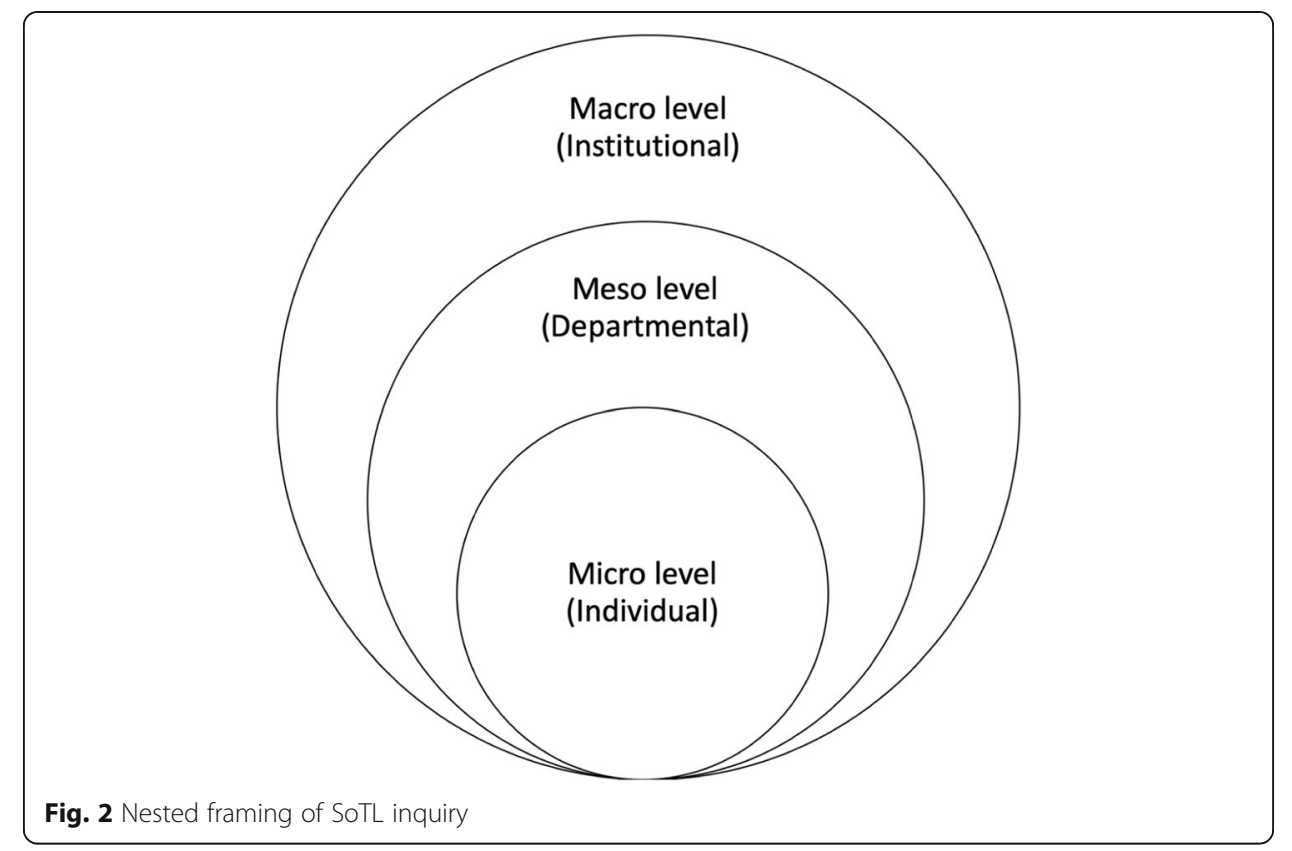

McDermott, Jacobsen and Brown, 2017). Because so little research has been conducted on contract cheating in Canada (Eaton, 2018; Eaton \& Edino, 2018) we chose an exploratory approach. As Gernsbacher (2018) pointed out, "exploration is a valid and important mode of scientific inquiry. .. vital for discovery" (p. 3).

\section{Method}

The main question that guided our inquiry was as follows: How do our respective institutions address the problem of contract cheating? A subquestion was also considered: How might a teaching and learning lens be explicitly used to engage in an inquiry on contract cheating? To help with these questions, each of the four researcher-participants reflected on a short series of questions in order to independently generate a written narrative:

1. Have you ever personally encountered contract cheating in a student's work? If yes, how did you deal with it?

2. If you have not encountered contract cheating in any student work, how equipped do you feel to detect it?

3. What conversations have you had with colleagues about the topic?

4. What do you think needs to be done about it?

5. How is your institution addressing it?

6. What else would you like to learn about it?

7. How do you think institutions can collaborate more or better to share learning?

The four written narratives became data sources. After reading one another's narratives, we came together to identify emerging themes.

\section{Analysis}

We engaged in a process of critical reflexivity as participant-researchers (Gemignani, 2017; Goldstein, 2017) throughout our inquiry, which consisted of iterative activities we 
executed as individuals and as a collaborative inquiry team. We conducted formal team meetings in which we met face-to-face to engage in discussion about our experiences, learnings, and reflections, as well as changes that were happening at our respective institutions over the course of our project. During our formal meetings, we also shared resources and institutional documentation, such as academic calendars, policies, and procedures. We supplemented these meetings with informal communications via e-mail and the use of a shared Google folder, which we used to archive materials, as well as engage actively in data analysis and prepare knowledge mobilization activities. We documented our individual reflections as written narratives, which formed the foundation of our data. Our reflections were not only individual but also collaborative and dialogic. Through a process of group reflection and active engagement in collective critical reflexivity, we moved through a process of collaborative knowledge-building (Simmons et al. 2017).

Although Fig. 3 represents our research process as linear and explicit, it was both iterative and organic. We found that we were able to articulate the inquiry itself only as a kind of meta-cognitive reflection about the research as a process.

Each researcher-participant analyzed their own narrative and, following the work of Saldaña (2016), coded individual ideas according to themes. In subsequent formal team meetings, the thematic analysis was further negotiated until all ideas were coded. This collaborative and interactive thematic analysis resulted in the emergence of five key themes, along with related subthemes.

\section{Findings}

Five key themes materialized from the analysis of the data: types of contract cheating, students, awareness, evidence and policy implications, and educational development.

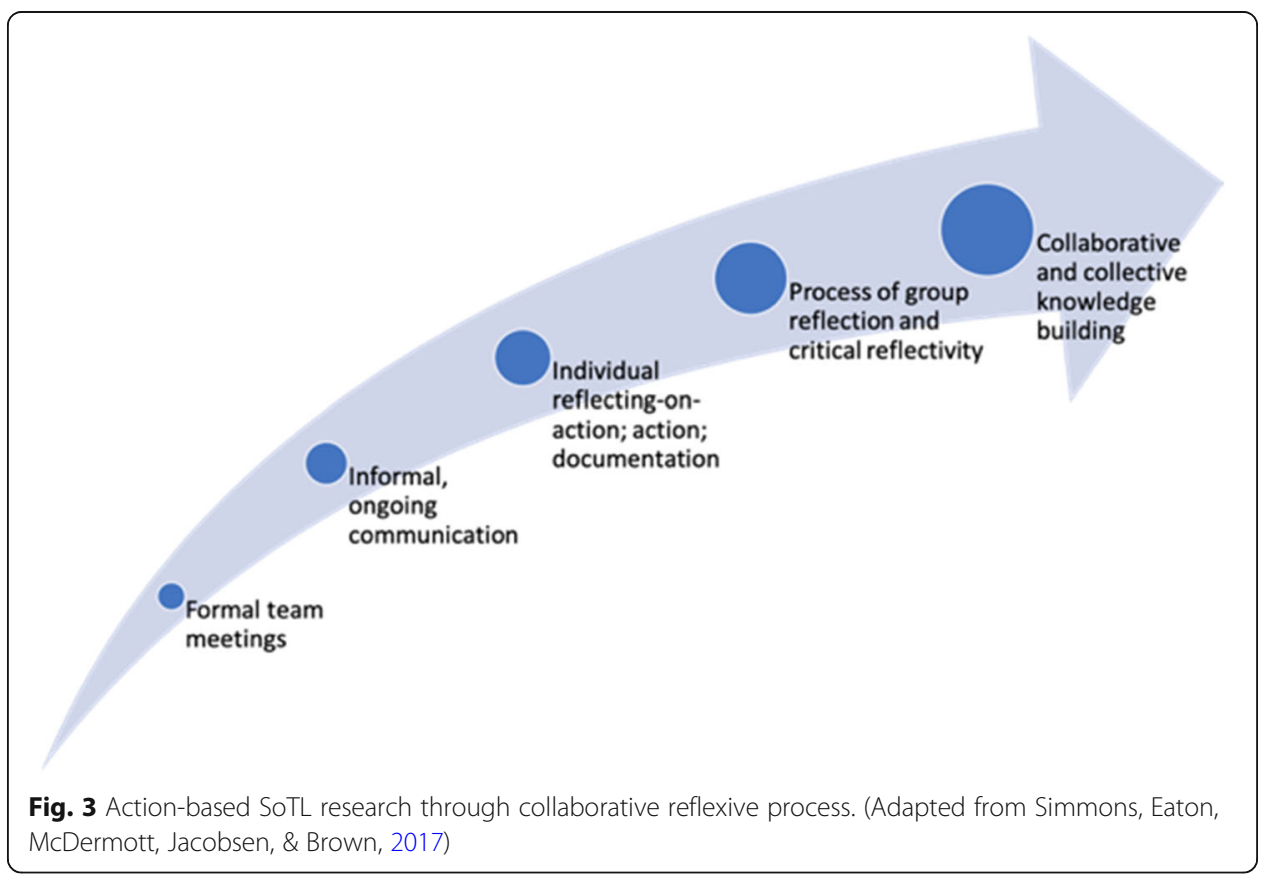


Theme 1: types of contract cheating

The data showed that the types of contract cheating to which the researchers had been exposed across all three institutions were paid sources, friends and family, and assignments previously submitted for the same course.

\section{Paid sources}

Paid sources of contract cheating mainly occurred through the internet. Through a variety of online sources, students could pay to get access to ready-made essays, assignments, lab reports, and computer code, or pay for someone to produce their academic work. An example in the data is one where Instructor A in 2018 discovered through Turnitin (plagiarism detection software) that a student's assignment was very similar to an assignment submitted to Instructor B in 2017. The essays made the same arguments about two different literary texts. Conversations with the students led the instructors and administrator to determine that both students had obtained the same essay from an online source. Online companies lure students in with promises of free online writing help, which is conditional upon the student uploading the documents that they are seeking help with. These companies keep the uploaded material and then sell that material to other students. In one situation we encountered, a student used such a website to run their computer code to verify that it worked. The website kept that code, and another student in the same class was able to purchase it. Less frequently than the use of online sources, students were also found to pay individuals for help in real life. In a specific example, one paid tutor gave two students, who claimed that they did not know each other, the same code to submit for their computer science assignment.

\section{Friends and family}

Friends and family emerged as another source of contract cheating in our study. Examples from our experiences included cases where a boyfriend had written a student's assignment, a sister in a different country had written a student's assignment, and a father of two students had written almost all the code for the students' computer science assignment. One researcher had the following reflection about her discussion with a student about loyalty contract cheating: "The conversation was memorable for me because I had to work surprisingly hard to help the student understand that having [someone else] write entire paragraphs of her paper was not acceptable."

\section{Previously submitted assignments}

The use of a previously submitted assignment was a common occurrence in the experiences shared, and this type of contract cheating relates to both paid sources, as well as friends and family. For example, one student stated that they had paid for help with an assignment on a website, and that website provided the student with a solution to the lab report assignment from the previous year's course. The questions differed slightly, and that is how the academic misconduct was detected. More commonly, though, students shared their assignment (from a previous semester or from a current class) with their friends. Those who shared often reported that they did so to help a friend who was struggling with the assignment. The intent of those students who shared their work was to show the friend how they approached the assignment rather than to give them 
content to submit as their own. As one of the researchers noted, "Often, the person who provided the assignment thought they were just helping their friend-giving them an idea of what they did. They didn't realize their friend was going to copy the whole thing or parts."

\section{Theme 2: students}

The second theme that emerged from the data was students, specifically what motivates them to engage in contract cheating, and how their previous learning experiences contribute to this behaviour. We noted that the primary motivation we encountered was a need to alleviate stress. As one researcher noted, "Many students are under significant pressure. More students seem to work more hours in addition to studying full-time." Many students were overwhelmed by schoolwork at specific times during a semester and could not see how they would find the time to complete the work. The opportunity to take even one thing off a student's to-do list through contract cheating can be hugely tempting. One researcher wrote in a narrative, "The majority of students that I have met with for academic misconduct were overwhelmed by school work and life events. They cheated the system to get one thing off their plate, hoping to alleviate some of the pressure they faced."

The experiences shared in the narratives showed that for international students, there might be additional pressure. One researcher noted, "International students are often under tremendous pressure to succeed (family expectations, much higher tuition, etc.)." Another source of pressure is a lack of English-language proficiency, not only for international students but also for many domestic students for whom English is an additional language. Sometimes students have met the official minimum language proficiency requirements, but as one researcher's narrative shared, "[if] they are underprepared for sophisticated writing assignments, they could be tempted to resort to contract cheating."

We observed that previous learning experiences, and indeed life experiences, impacted a student's engagement in contract cheating. One of the narratives reflected on the prevalence of the Internet in sourcing information on a daily basis: "The World Wide Web allows us to share information on a massive scale. Our students are being brought up in an environment where the sharing of information is now common practice. Uploading essays, tests, labs, and assignments for many students is seen not as academic misconduct, but as the sharing of information. Students clearly recognize that paying for work is academic misconduct, but [they] mistakenly view getting it for free and using it as merely part of gathering research."

For students whose previous learning experiences have been in other countries, it is possible that academic integrity was viewed quite differently in their previous institutions. As one of the researchers wrote, "An additional layer. .. is the question of what is considered ethical/unethical in particular cultures? Where is the line between ethical and unethical?" They provided an example of an individual who revealed that it was common practice in their home university to pay a professor for copies of previous assignments.

\section{Theme 3: awareness}

Awareness of contract cheating at the individual level and at the institutional level was prevalent as one of the key themes. Regarding educator awareness, one of the researchers gave a presentation on contract cheating in April 2018 that the other three 
researchers attended. These three others each shared in their narratives a sense of astonishment at the accessibility of contract cheating and the number of companies offering this service. One researcher shared: "My eyes were opened to the term contract cheating and to the practice itself at [the presentation]. I had not understood its prevalence. I would have naively said that it doesn't happen at [my institution], simply because we had never found it."

Two narratives also expressed shock at the cost that students were willing to pay for assignments. One reported, "Colleagues and I were shocked at how easy it was to negotiate a price for 150 pages of a dissertation draft (a live negotiation we observed during the workshop)." One member of the research team had some awareness of the existence of contract cheating in undergraduate work but not graduate work, and another researcher mentioned having thought paid source contract cheating was an issue in the United Kingdom but not in Canada. Two of the researchers reflected in their narrative that they had never heard of contract cheating being discussed at their respective institutions. One researcher shared conversations with colleagues where the colleagues dismissed contract cheating as a non-issue. This spoke to a general lack of awareness about contract cheating among post-secondary educators in Canada.

Awareness at the student level emerged as a subtheme in the data analysis. Specifically, the researchers reflected on the importance of discussing contract cheating, among other forms of academic misconduct, with students from the outset. One researcher reflected, "When I talk to students informally, some of them have shared. .. that they didn't think this was even on their professor's radar. They think profs just don't know how easy it is for them to buy academic work online." The hope is that discussing it openly with learners will discourage them from engaging in it, communicate to them that educators are in fact aware of it and looking out for it, and encourage them to become advocates for academic integrity.

Awareness at the institutional level is another important subtheme that became apparent. This research project showed that individuals raising awareness of contract cheating at their home institutions, and learning from and sharing with other institutions, is beneficial. One of the researchers wrote, "Reading about and sharing what other institutions are doing has been helpful. It's important to share the message that individual educators, administrators and institutions are not alone. When we share ideas, experiences and approaches we learn from and with each other. In turn, this helps us to have more conversations with more colleagues."

The researchers' three institutions have participated in the International Day of Action Against Contract Cheating to varying degrees since 2017. At one institution, the Office of Student Conduct set up a booth in a high-traffic area of campus to talk with students. At another institution, the library set up a booth at a similarly busy spot to promote academic integrity to students. The third institution hosted a campus-wide lunch and learn in 2017 and in 2018. Thomas Lancaster, a UK-based specialist in contract cheating, was invited to speak via Skype to campus stakeholders at the 2018 lunch and learn. Clark and Lancaster (2006) coined the term contract cheating and Lancaster, in particular, has remained an active researcher in the field. This sets a strong example of one of the many issues educational integrity in Canada is facing with few individuals having developed sustained programs of research in the area (Eaton \& Edino, 2018). In the case of the third institution, only about a dozen individuals from across the campus 
attended the lunch time events each year, pointing to a general lack of awareness about contract cheating.

One of the researchers' reflections also considered the importance of engaging parents and community stakeholders regarding academic integrity: "They need to know that the academy is keeping up with the times and acknowledging that while the Internet may have changed how students cheat, as an institution, our values around integrity remain constant."

\section{Theme 4: evidence and policy implications}

The data showed there is debate and concern among faculty and administrators about how much and what type of evidence of contract cheating is needed in order to address it with the student and to impose a sanction. For example, in one narrative a researcher shared the experience of talking to faculty who, "are sure that the student didn't write it, but they don't have proof. And we have both left it there because of the notion of having proof being important." Similarly, another researcher reflected in a narrative, "I have observed that my initial conversations with colleagues resulted in a kind of defeatist response. 'We can't prove it, so there is nothing we can do." This frustration was common among the participant-researchers, whose institutions consistently required educators and administrators to have an "air tight" case to move a case of academic misconduct forward.

One researcher was motivated to think differently about the need for evidence through engagement in this cross-institutional project as well as interactions with a particular colleague. That colleague provided the researcher with a simple reminder that a conversation with a student about suspected contract cheating does not happen in a court of law, where the burden of proof is required to impose a sanction. That colleague shared an example whereby they spoke with a student and asked questions about how the student found and determined which sources to use in the assignment. The student's answers indicated that they were not actually familiar with the sources that were listed in the assignment.

The data included accounts of detecting contract cheating. In one case, as the researcher described, "I had noticed that the voice and proficiency level of [the] writing changed quite radically from one paragraph to the next. There was suddenly sophisticated vocabulary and significantly more accurate grammar than in the previous paragraph." The educator then asked the student to explain the meaning of certain vocabulary terms, and the student could not explain. In another case, contract cheating was first detected because the student's submission did not address the specific assignment instructions. An author's work was on the list of texts the student could choose to analyze, and the student used a different text by the same author.

The latter example of contract cheating detection is one that addresses the matter of evidence. The educator met with the student, and when the student was asked questions about arguments made in the assignment they submitted, they stated that they did not remember what they had written. The educator told them that there was concern that the student had not written the assignment, and twice in the conversation the student said, "You have no proof." After the second mention of proof, the educator suggested the sources from which they thought the student may have drawn the assignment they submitted. The student's focus then shifted to questions about taking the course again and the implications of academic misconduct. The educator, much more aware of the prevalence of contract cheating through this interinstitutional collaborative 
research, provided this reflection regarding proof: "What's important to me is that I didn't get bogged down in the 'no proof' argument. I proceeded, confident in my determination that this wasn't their writing, even if I wasn't sure where the writing came from."

The data show a desire from faculty to have contract cheating addressed in policy, with specific examples outlined. One narrative related a faculty member's request for institutional policy to make specific mention of the type of cheating we herein refer to as paid source. In another narrative, the researcher was encouraged by proposed changes to the academic misconduct policy at her institution: "I was recently invited to review a draft and I was really pleased to see that contract cheating is being addressed more explicitly.. .. The term 'contract cheating' is not used, but examples are given and it is more explicit that when students have someone complete academic work on their behalf, it is considered misconduct." The proposed policy has since been approved, and it includes the following example of plagiarism: "purchasing, or otherwise acquiring work and submitting it as the Student's own original work" (University of Calgary, 2019b, p. 4).

\section{Theme 5: educational development}

The fifth theme that surfaced from the data was educational development for students and for educators.

Educational development for students involves communicating with them about contract cheating. One of the researchers recommended sharing with learners examples of academic misconduct specific to a course and its assessments and discussing ways to avoid making those choices. The narratives considered the importance of letting learners know that faculty are aware that contract cheating exists and are looking out for it. This reflects the recommendation made by Bretag (2019), who implored educators to be frank with learners about the many opportunities to engage in contract cheating that are available to them and to discuss the importance of academic integrity with them. In addition, one of the researchers recommended engaging students in advocacy work in support of academic integrity.

Supporting students as learners is another key aspect to educational development. Time management came up in the data as a challenge students face and one that some choose to overcome through contract cheating. Educators can consider the volume and timing of assessments and make adjustments to reduce the appeal of contract cheating. Providing assignment extensions also mitigates contract cheating. Additional academic success centre programming on research, writing, referencing and time management could also be beneficial to students. One researcher described her institution's existing bridging program for new post-secondary students, noting that "a major learning outcome for the program is to help participants become aware of the supports that exist -both online and in person -- to help them with writing/time management." The program provides participants with scenarios where students might be tempted to engage in contract cheating due to time pressure and helps them understand where they can turn for help that is in line -- as opposed to out of line -- with academic integrity.

Educational development for faculty involves providing them with resources, including financial and time resources, to increase awareness of contract cheating and detection strategies, but more importantly to create assessments that will promote academic integrity and discourage contract cheating. Resources could include professional development around assessment design, opportunities to share with other faculty about 
assessments, a repository of contract cheating-proof assessments, teaching assistants assigned to take on any additional marking that new assessment types might bring, teaching assistants to help with assessing individuals within class time, and detection (i.e. text-matching) tools that are easily accessible (e.g., MOSS) and can work in tandem with an institution's learning management system (e.g., Turnitin, as integrated with Desire to Learn Brightspace).

\section{Limitations}

Our findings are limited by three factors. First, all three institutions involved in this project are located in Alberta, Canada. No formal regional academic integrity network existed in this province at the time of this study, resulting in barriers to educators and administrators wanting to share ideas and resources on this topic. The project was undertaken, in part, to begin an exchange of knowledge and practices between institutions. In the province of Ontario, the Academic Integrity Council of Ontario (n.d.) already functions as "a forum for academic integrity practitioners and representatives from post-secondary institutions to share information, and to facilitate the establishment and promotion of academic integrity best practices" (para. 1). Thus, the impetus for and impact of a project like this would be different in a province such as Ontario. The second limitation is that the three institutions are all located in the city of Calgary. Post-secondary institutions in smaller urban centres are not represented, and it could be that contract cheating takes different forms and requires distinct responses and interventions in institutions located in smaller cities. The final limitation is that all four researcher-participants are employed by their respective institutions; students and teaching assistants were not recruited for this project. Student and teaching assistant input would undoubtedly further shape the discussion and interventions recommended.

\section{Implications and impact}

This project has impacted the researcher-participants on three different levels: individually, intrainstitutionally, and interinstitutionally. One of the researchers had already engaged in research on contract cheating (Eaton, 2018); the other three researchers' individual awareness and understanding of contract cheating were dramatically increased through this project. Having learned about detection strategies, we are now more attuned to identifying instances of contract cheating and have been actively sharing these strategies with colleagues at our home institutions. We are more prepared to discuss contract cheating with students, whether those discussions take place in individual meetings when a student is suspected of having engaged in contract cheating, in the classroom, or in workshops whose learning outcomes connect to academic integrity.

This growing understanding of contract cheating has also prompted us to mobilize knowledge at our institutions in more formal ways. Educational development sessions for faculty members have been organized at all three institutions over the past year. Events for students have included whiteboard declarations to coincide with the International Day of Action Against Contract Cheating and, at one institution, an entire Academic Integrity Week in fall 2018.

Finally, our collaboration has generated opportunities for interinstitutional sharing. We compared institutional policies and procedures at our respective institutions, 
considering both the merits and drawbacks of the different systems. Some institutions specifically address contract cheating in their policies, whereas others do not. One institution has developed an academic integrity website that educates students about "payto-pass" companies that might engage in contract cheating, unethical tutoring, and so on (University of Calgary, 2019a).

Opportunities to expand professional networks have come to us through invitations to speak at each other's campuses and through presentations at conferences that we would not otherwise have attended since these conferences are outside our academic disciplines. Importantly, this project has made us feel supported, moving forward. As one researcher noted in a narrative, the work we are doing is "part education, part advocacy and part encouragement. When we find out how other individuals and institutions are tackling this problem, we realize we are not alone, [and] that is important."

Hutchings and Shulman (1999) articulated that SoTL happens when researchers "frame and systematically investigate questions related to student learning - the conditions under which it occurs, what it looks like, how to deepen it, and so forth - and do so with an eye not only to improving their own classroom but to advancing practice beyond it" (p. 13). In our project we have paid particular attention to the notion of advancing practice beyond our own classrooms and institutions. As we reflect on our SoTL inquiry through nested perspectives (Fig. 2), we observe that a contribution to the field of SoTL is an expansion on this concept to show how intentional collaboration between and among colleagues can add an additional dimension to this type of scholarly inquiry. We have pushed the boundaries of our work beyond our individual institutions though sustained and purposeful collaboration as colleagues from different institutions. By moving our work beyond the institutional (macro-level), we have expanded it to a new level: a mega-level, which extends beyond our individual institutions to our professional community more broadly. In a country where educational integrity research has suffered, in part, due to lack of collaboration between researchers from multiple institutions (Eaton \& Edino, 2018), our project helps to pave the way for more sophisticated collaborations over time.

Figure 4 offers a visual representation of how our inter-institutional perspectives have advanced the framing of SoTL research, adding layers of complexity and interconnectedness that are needed to advance scholarship in this field.

In some ways, Fig. 4 is an over-simplification of our project, but it nevertheless shows a basic representation of our original contribution to the field of academic integrity research from a SoTL perspective. SoTL can help educators "to find common ground within and across disciplines by engaging the scholarly community in critical educational issues" (Hubball \& Clarke, 2010, p. 1). We have not only engaged across disciplines, but across institutions. Our collaboration has shown the importance of extending SoTL research beyond the individual (micro level), departmental (meso level), and institutional (macro level) (Kalu et al., 2018; Kenny et al., 2016) to include systematic inquiry between, among, and beyond all of these to carry the conversation to a broader level that is connected to the broader professional community, which in our case is higher education. We recognize that a possible next step for this work is to extend it even further, into conversations beyond higher education to other contexts such as K-12 education and possibly even at the societal level. This is work that has yet to be developed or undertaken. 


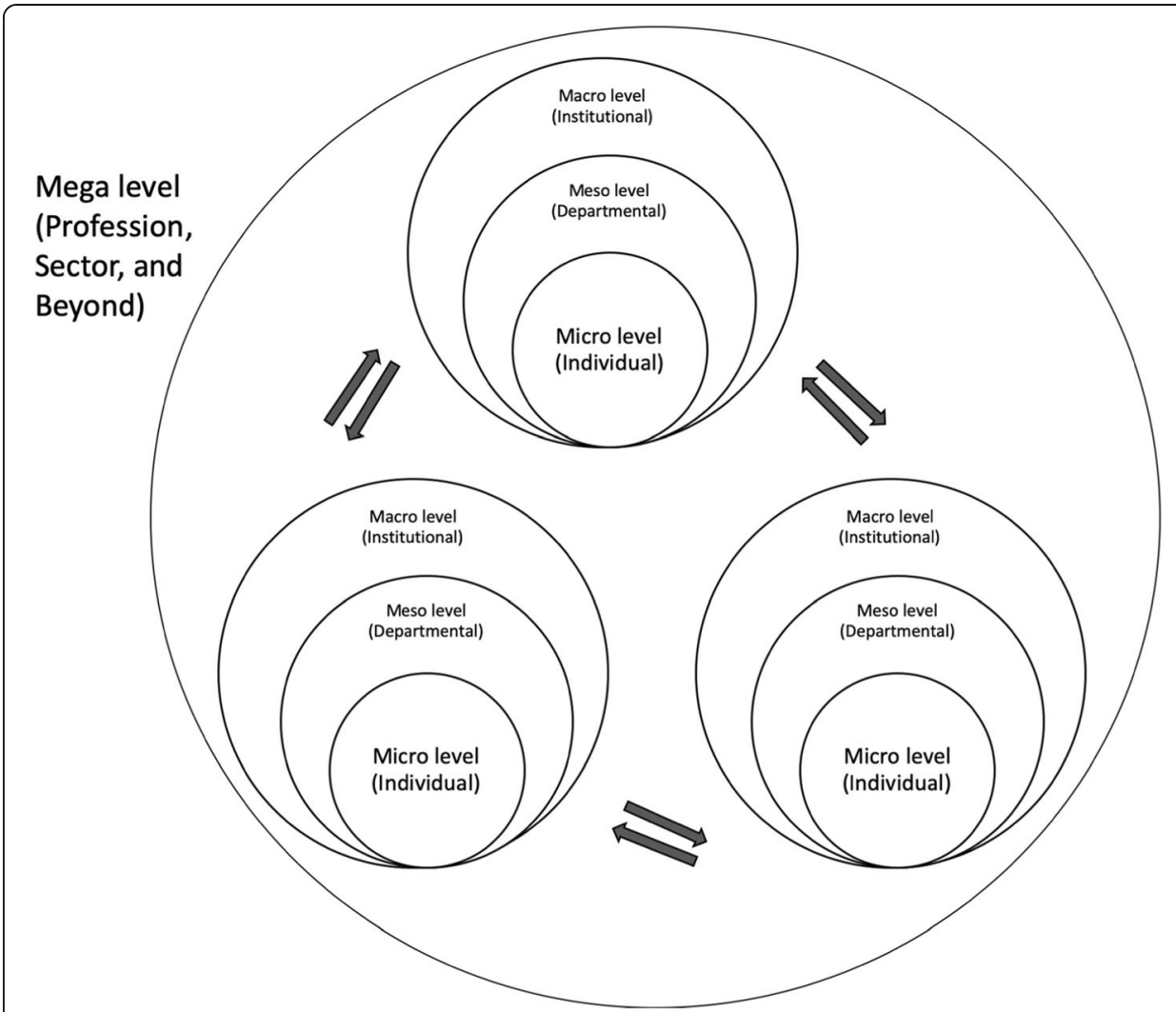

Fig. 4 Inter-institutional framing of SoTL, situated within a broader professional context

To the best of our knowledge, little research of any kind has been published to date on contract cheating in Canada, where research on educational integrity lags behind other nations (Eaton \& Edino, 2018). It is our hope that through this small, qualitative study, we begin to launch a process of scholarly inquiry into contract cheating within Canada. A key finding from our study is that we are stronger when we work together. We began our project as four professionals with no prior connection to one another. Through our collaboration, we have each grown professionally and become leaders in both formal and informal ways at our respective institutions.

Most recently, we have been involved in the development and launch of a provincial network designed to connect professionals from across our entire region, the Alberta Council on Academic Integrity (ACAI). The network is developing in similar ways to our small-scale project. Colleagues who were previously unacquainted have committed to working together with a singularity of purpose, which is to help and support one another as we tackle complex issues related to educational integrity broadly. Each of us has contributed to the development of the network in different ways, with some taking on leadership roles, others participating and others still acting as a sounding board and supporter. We are confident that the network will develop over time as colleagues work together, building their knowledge, competence, capacity, knowledge and courage. Although the network is still very much in its infancy, it is clear to us that its development and launch would likely have been slower and clumsier if we had not already developed a strong sense of confidence that not only is collaboration possible, it is critical if we are to develop the field of academic integrity. 


\section{Conclusions}

The purpose of this study was to explore experiences with contract cheating as educators in various roles across three post-secondary institutions. The data sources for this research included reflective narratives about professional practice, observations of the variety of institutional initiatives to address academic integrity (e.g. faculty development workshops, awareness events), and institutional documentation and policies relating to academic integrity.

Five major themes surfaced from the analysis of the data: types of contract cheating, students, awareness, evidence and policy implications, and educational development. Key findings included that students engage in contact cheating to alleviate the pressure they feel; the most common type of contract cheating is the use of a paid online source; despite the proliferation of contract cheating, faculty and administrators have little awareness of its existence; and as such there is a need for contract cheating to be addressed in institutional policy and for it to be discussed openly among faculty and students. As researcher-participants, we reflected that engaging in this interinstitutional project was beneficial to each of us in that it increased our awareness of contract cheating, increased our confidence in and strategies for addressing contract cheating with students, and fostered interinstitutional knowledge mobilization. From here, Canadian scholars and educators are situated to amplify research into contract cheating in this country. In addition to qualitative, self-reported practitioner-researcher data such as that we have presented here, the time is upon us to gather data from students, providers, and others on this topic.

\section{Abbreviation}

SoTL: scholarship of teaching and learning

\section{Acknowledgements}

We thank our respective institutions: University of Calgary, Bow Valley College, and Mount Royal University for the institutional in-kind support provided to us to undertake this work.

\section{Authors' contributions}

SEE (25\%); MAT (25\%); SR (25\%); NC (25\%). SEE conceptualized and designed the project. All authors analyzed the data and drafted the manuscript. All authors read and approved the final manuscript.

Authors' information

Sarah Elaine Eaton is a full-time faculty member at the Werklund School of Education, University of Calgary, Alberta, Canada. Nancy Chibry is an Associate Dean - Undergraduate Programs and Student Affairs in the Faculty of Science, University of Calgary, Alberta, Canada.

Margaret A Toye is Associate Dean - Human Services and Social Sciences in the School of Community Studies, Bow Valley College, Calgary, Alberta, Canada.

Silvia Rossi is a Writing and Learning Strategist in Student Learning Services at Mount Royal University, Calgary, Alberta, Canada.

Funding

No external funding was received.

Availability of data and materials

Data can be shared upon request, at the discretion of the authors.

Competing interests

The authors declare that they have no competing interests.

\section{Author details}

${ }^{1}$ Werklund School of Education, University of Calgary, Calgary, Alberta, Canada. ${ }^{2}$ Faculty of Science, University of Calgary, Calgary, Alberta, Canada. ${ }^{3}$ School of Community Studies, Bow Valley College, Calgary, Alberta, Canada.

${ }^{4}$ Student Learning Services, Mount Royal University, Calgary, Alberta, Canada. 
Received: 28 July 2019 Accepted: 9 October 2019

\section{Published online: 09 December 2019}

\section{References}

Academic Integrity Council of Ontario (n.d.) About AICO. Retrieved from https://academicintegritycouncilofontario.wordpress. com Accessed 15 May 2019.

Adam L (2016) Student perspectives on plagiarism. In: Bretag T (ed) Handbook of academic integrity. Springer Singapore, Singapore, pp 519-535

Bertram Gallant T (2008) Academic integrity in the twenty-first century: A teaching and learning imperative. Wiley, Hoboken, NJ

Bertram Gallant T, Kalichman M (2011) Academic ethics: A systems approach to understanding misconduct and empowering change in the academy. In: Bertram Gallant T (ed) Creating the ethical academy: A systems approach to understanding misconduct and empowering change in higher education. Routledge, New York, NY, pp 27-44

Boyer EL (1990) Scholarship reconsidered: Priorities of the professoriate. The Carnegie Foundation for the Advancement of Teaching, New York

Bretag T (2019) Contract cheating research: Implications for Canadian universities. Paper presented at Canadian Symposium on Academic Integrity, University of Calgary, April 17-18, 2019. Calgary, Canada.

Bretag T, Harper R, Burton M, Ellis C, Newton P, van Haeringen K et al (2019) Contract cheating and assessment design: Exploring the relationship. Assessment Evaluation in Higher Educ 44(5):676-691. https://doi.org/10.1080/02602938.2018.1527892

Clarke R, Lancaster T (2006) Eliminating the successor to plagiarism: Identifying the usage of contract cheating sites. Paper presented at the Second International Plagiarism Conference, The Sage Gateshead, 19-21 June, 2016. Tyne \& Wear: United Kingdom.

Curtis GJ, Clare J (2017) How prevalent is contract cheating and to what extent are students repeat offenders? J Acad Ethics 15(2):115-124. https://doi.org/10.1007/s10805-017-9278-x

Eaton, SE (2018). Contract cheating: A Canadian perspective. Retrieved from http://blogs.biomedcentral.com/bmcblog/2018/ 07/24/contract-cheating-a-canadian-perspective/

Eaton SE, Edino RI (2018) Strengthening the research agenda of educational integrity in Canada: A review of the research literature and call to action. Int J Educ Integr 14(1). https://doi.org/10.1007/s40979-018-0028-7

Ellis C, Zucker IM, Randall D (2018) The infernal business of contract cheating: Understanding the business processes and models of academic custom writing sites. Int J Educ Integr 14(1):1-21.https://doi.org/10.1007/s40979-017-0024-3

Fanghanel J (2013) Going public with pedagogical inquiries: SoTL as a methodology for faculty professional development Teach Learn Inq 1(1):59-70. https://doi.org/10.2979/teachlearninqu.1.1.59

Gemignani M (2017) Toward a critical reflexivity in qualitative inquiry: Relational and posthumanist reflections on realism, researcher's centrality, and representationalism in reflexivity. Qual Psych 4(2):185-198

Gernsbacher MA (2018) Writing empirical articles: Transparency, reproducibility, clarity, and memorability. Adv Methods Pract Psychol Sci 1(3):1-12. https://doi.org/10.1177/2515245918754485

Goldstein SE (2017) Reflexivity in narrative research: Accessing meaning through the participant-researcher relationship. Qual Psych 4(2):149-164

Hosney MI, Fatima S (2014) Attitude of students towards cheating and plagiarism: University case study. J Appl Sci 14(8):748757. https://doi.org/10.3923/jas.2014.748.757

Hubball H, Clarke A (2010) Diverse methodological approaches and considerations for SoTL in higher education. Can J for the Sch of Teach and Learn 1(1). https://doi.org/10.5206/cjsotl-rcacea.2010.1.2

Hubball H, Pearson ML (2013) SoTL inquiry in broader curricular and institutional contexts: Theoretical underpinnings and emerging trends. Teach Learn Inq 1:41-57. https://doi.org/10.20343/teachlearninqu.1.1.41

Hutchings P, Shulman LS (1999) The scholarship of teaching: New elaborations, new developments. Change: The Magazine of Higher Learning 31(5):10-15. https://doi.org/10.1080/00091389909604218

Kalu F, Dyjur P, Berenson C, Grant KA, Jeffs C, Kenny N, Mueller R (2018) Seven voices, seven developers, seven one things that guide our practice. To Improve the Academy 37(1):111-127. https://doi.org/10.1002/tia2.20066

Kenny N, Watson GPL, Desmarais S (2016) Building sustained action: Supporting an institutional practice of SoTL at the University of Guelph. New Directions for Teaching and Learning 2016(146):87-94. https://doi.org/10.1002/tl.20191

Lancaster T [DrLancaster] (2018) Just reading comments from essay mill marketers in a blackhat forum in preparation for a talk next week [Tweet]. https://twitter.com/DrLancaster/status/1029014675198013440. Accessed 8 July 2019.

Lancaster T, Clarke R (2008) The phenomena of contract cheating. In: Roberts TJ (ed) Student plagiarism in an online world: Problems and solutions. Idea Group, Hershey, pp 144-158

Mahmud S, Bretag T, Foltýnek T (2019) Students' perceptions of plagiarism policy in higher education: A comparison of the United Kingdom, Czechia, Poland and Romania. J Acad Ethics 17(3):271-289. https://doi.org/10.1007/s10805-018-9319-0

McDonald, J., Kenny, N., Kustra, E., Dawson, D., labal, I., Borin, P., \& Chan, J. (2016). Educational Development Guide Series: No. 1.: The Educational Developer's Portfolio. Retrieved from https://www.stlhe.ca/wp-content/uploads/2016/03/ED-GuideNo1_The-Educational-Developers-Portfolio_Final.pdf

McNiff J (2010) Action research for professional development: concise advice for new action researchers. September Books, Poole McNiff J (2013) Action research: principles and practice. Routledge, New York

McNiff J (2014) Writing and doing action research. Sage, Thousand Oaks

Newton P (2018) How common is commercial contract cheating in higher education? Front Educ. https://doi.org/10.3389/ feduc.2018.00067

O'Brien M (2008) Navigating the SoTL landscape: A compass, map and some tools for getting started. Int I Sch Teach Learn 2(2) https://digitalcommons.georgiasouthern.edu/cgi/viewcontent.cgi?article=1109\&context=ij-sotl.

Owings S, Nelson J (2014) The essay industry. Mountain Plains J Bus Econ 15:1-21 http://www.mountainplains.org/articles/2 014/General\%20Research/Mountain_Plains_Journal_of_Business_and_Economics_Volume_15_2014_1-21_General_ Research_Owings.pdf.

Quality Assurance Agency for Higher Education (2017) Contracting to cheat in higher education: How to address contract cheating, the use of third-party services and essay mills. https://portal.uea.ac.uk/documents/6207125/21947903/ltc1 7d031+qaa+guidance+contract+cheating+in+he.pdf/310aaffe-5201-7a21-1f35-3a345e56a378. 
Rigby D, Burton M, Balcombe K, Bateman I, Mulatu A (2015) Contract cheating \& the market in essays. J Econ Behav Organ 111:23-37. https://doi.org/10.1016/j.jebo.2014.12.019

Rogerson AM (2017) Detecting contract cheating in essay and report submissions: process, patterns, clues and conversations. Int J Educ Integr 13(1):10. https://doi.org/10.1007/s40979-017-0021-6

Saldaña J (2016) The coding manual for qualitative researchers, 3rd edn. Sage, Thousand Oaks

Simmons M, Eaton SE, McDermott M, Jacobsen DM, Brown B (2017) Situating action research in the scholarship of teaching and learning: Reflecting on curriculum mapping and review. Paper presented at the International Society for the Scholarship of Teaching and Learning (iSSOTL), 14 October, 2017. Calgary, Canada

University of Calgary. (2019a). Student Academic Misconduct Policy. Retrieved from https://www.ucalgary.ca/policies/files/ policies/student-academic-misconduct-policy.pdf

University of Calgary. (2019b). What you need to know about paying for academic support. Retrieved from https://ucalgary. ca/current-students/paying-for-academic-support

Walker M, Townley C (2012) Contract cheating: A new challenge for academic honesty? J Acad Ethics 10(1):27-44. https://doi org/10.1007/s10805-012-9150-y

\section{Publisher's Note}

Springer Nature remains neutral with regard to jurisdictional claims in published maps and institutional affiliations.

\section{Ready to submit your research? Choose BMC and benefit from:}

- fast, convenient online submission

- thorough peer review by experienced researchers in your field

- rapid publication on acceptance

- support for research data, including large and complex data types

- gold Open Access which fosters wider collaboration and increased citations

- maximum visibility for your research: over $100 \mathrm{M}$ website views per year

At $\mathrm{BMC}$, research is always in progress. 